\title{
Yes We Should; Research Assessment in the Humanities
}

\author{
Wiljan van den Akker
}

\begin{abstract}
In this contribution I argue that the Humanities, just like any other mature field of knowledge, should have or develop a system by which its research can be assessed. In a world that increasingly asks for justification of public funds, where public money becomes scarcer, so that less amounts have to be distributed among more players, where research funds are being concentrated and distributed on a highly competitive basis, we as humanists cannot shy away from research assessment with the argument that 'we are different from the rest' or that 'we don't need it'. Of course the humanities are a distinct member of the body of academic knowledge, but that holds true for every discipline. If we agree that for instance that bibliometry does not suit most players in our field, the question becomes: what will suit us better? Case-studies? This contribution also contains a warning: let us stop arguing about the language issue. English is the modern Latin of academia and its use enables us to communicate with one another, wherever we are or who we are. Without providing definite solutions, my argument is that we, humanists, should take the steering wheel ourselves in developing adequate forms of research assessment. If we leave it to others, the humanities will look like arms attached to a foot.
\end{abstract}

Suppose that I have learned something during the more than 25 years I am working within the humanities now - as a teacher, a researcher, a director and a dean. The attitude of my field towards research-assessment in any form, can be summed up as follows. 'We don't want it, because we don't have to, because we don't need it, because we are not like the others, and therefore we don't like it, and they shouldn't force us, because they don't know us, because they don't understand us, because they don't love us.' The image of the humanist working in solitude in the attic, writing a book that will replace all existing books and render superfluous all books that have not yet been written, is still alive and kicking.

The humanities have developed several defense-mechanisms against research assessment in general. I will name only three of them.

\footnotetext{
W. van den Akker

Utrecht University, Kromme Nieuwegracht 46, 3512 HJ Utrecht, Netherlands

e-mail: W.J.vandenAkker@uu.nl

M. Ochsner et al. (eds.), Research Assessment in the Humanities,

DOI 10.1007/978-3-319-29016-4_3
} 
1. The (much heard) argument of intuition: the quality of our research is not measurable, not quantifiable. We know quality when we see it. We have a perfect understanding of who is excellent and who is not. It is easy to see that although this argument may be (sometimes) true, it is also highly irrelevant. In fact, one could turn it around and say that this should make research assessment a lot easier, also the production of the top ten or top hundred. Anyone who has ever dared to ask such a question, knows that it equals a declaration of war.

2. A second mechanism is: the humanities as a whole are principally and practically completely different from all the other forms of science or knowledge fields, especially the hard sciences. But this is not true. There is not one common denominator that separates the humanities from the other academic fields. In fact the humanities are made of different disciplines and fields who hold their own positions within academia. Some are very familiar to fields like theoretical physics, like for instance linguistics. Others are close to social sciences, like for instance large parts of the historical disciplines. Some philosophers claim the same domain as mathematics.

3. The third defense mechanism mirrors the second: since there is no such identifiable and unifiable one thing as the humanities, since we are a habitat of different species, it is impossible to compare us to other parts of the body of knowledge. Again it is not a strong argument, since the same holds true for what we generally call the (hard) sciencesmedicinetechnical sciences, and so on and so forth. Think of the social sciences where the anthropological and the empirical approaches are totally different.

All these defense mechanisms are not effective for today's world and especially not for the future of the humanities. We cannot and should not insist on being 'different' just to shy away from any form of research assessment. If we continue doing that, we will be the young sister or brother who is tolerated at the dining table, at the mercy of the food that the rest of the family thinks it can spare and always looked down upon. Maybe with a friendly smile, but nevertheless.

In the near future, in a world that increasingly asks for justification of public funds, in a world where at the same time public money becomes scarcer and less amounts have to be distributed among more players, in a world where research funds are being concentrated and distributed on a highly competitive basis, we as humanists have to take the stand and declare that we are grownups who want to play the game.

Maybe our defense mechanisms were never effective in the past anyway, but the older brothers and sisters just left us alone, which could be one of the reasons that the humanities are underfunded in general, not only in research but especially in teaching. In that case we already have shot ourselves in the foot and it becomes a matter of healing as quickly as possible in order to be able to kick again real hard.

If we are not essentially different from other fields of academia, we also should recognize that, just like the other members of the family, we are not simple. It is clear that in discussing research assessment within the humanities, we are dealing with a complicated matter, complicated in the sense of a complex of several parameters, angles, similarities, issues etc. Just to name seven aspects: 
1. There are substantial differences in scientific practice between the several disciplines within the humanities. These differences can and will have consequences for the selection of quality indicators. There are areas where groups of scholars work together on a common project - say the testing of a theory-and therefore they publish together in journals and an analysis of citations can or will be useful. In other areas individuals work on diverse topics and therefore publish individually and therefore an analysis of citations can be less useful.

2. The rotation time of humanities articles and books. Contrary to many other fields of science, much of what we humanists produce can have an effect in the long(er) run. Consider the fact that much research in for instance medicine will be outdated within 2 or 3 years, or perhaps even sooner.

3. The goals and products of research are different in different areas of the humanities. Unlike scholars in, say theoretical physics, much research in the humanities has the intention and maybe even the assignment by society to guard, disclose, save and interpret international and/or national heritage. Even though not all scholars like it or accept it, society in general often looks at us in this way. If we don't do it, who else will? This means that the products of such research will and cannot be seen only in terms of articles in scientific journals, but for instance also in the construction of large databases and the opening up of large data collections, exhibitions with catalogues, excavations of archeological sites etc. Think of the endless amounts of historical or cultural material lying in archives, museums, libraries. Data collections, also including books, are for the humanities the laboratories that make the work of our relatives in the sciences so expensive.

4. As a consequence the target group of the humanities is diverse. On the one hand, like in any other scientific field, our accumulation of knowledge is targeted at our peers, on the other hand we have a large, non-academic audience to serve. One of the problems scholars in the humanities face, is to define this wider group and to justify our relations with it. What astronomers perhaps would see as translation of scientific knowledge, and therefore regard as journalistic of the profession, is for many humanists core business. But not always, and there we have an immense problem to solve. To be quite clear, I don't have the answer, but I do think a possible solution lies within the realm of peer review.

5. All this shows that the publication channels of the humanities will vary. In some fields traditional books are still the main or even the only accepted way to transfer our knowledge, like in many parts of history or literary studies. In some areas, however, articles in journals have replaced the more traditional book, like in linguistics. There, books are mainly written in order to popularize knowledge or to use in classrooms for teaching purposes.

6. A highly inflammable aspect related to all this, is the language of our scholarly work. Inflammable because often there is a nationalistic side in the discussion, even when it is hidden and not explicitly mentioned. The argument mostly goes like this: since my scholarly object is Dutch poetry, I cannot but write about it in Dutch. Because of the linguistic nature of the field of study, there have to be journals in a language other than English. Tied to this is the more sentimental reasoning: a country like The Netherlands has its own cultural heritage and acad- 
emia should honor the uniqueness of it, by allowing high quality scholarly work in Dutch.

Of course anyone can substitute Hungary or Switzerland for The Netherlands. Following this line, someone writing about Polish novels in Dutch, would not contribute to science, someone writing on the same subject in Polish on the other hand would. I am not convinced that this line of reasoning is strong enough but I also realize that my counter arguments are disputable and will be disputed.

First of all it is a mistake to think that most scholarly work is written in English. It looks and sounds like English but it is not. It is at the best Scholarly English, like Latin was centuries ago. The Latin those colleagues back then wrote and spoke in no way resembled the Latin from the Romans, as any specialist can confirm. It was agreed upon as the lingua franca of science, a fantastic way to communicate all over the world, regardless of one's country of origin and mother tongue. Seen from this point of view, there is no valuable reason why a scholar whose object is Dutch poetry should prevent the rest of the world to read his or her results by writing in Dutch about it. Why has the language of the object of research anything to do with the language in which we scholarly communicate about it? The mere fact that only a small part of the wide world is interested in Dutch poetry and a large part does not even know it exists at all, is totally irrelevant. Moreover: writing only in Dutch about Dutch poetry, will be absolutely the best guarantee that the world stays ignorant about the subject.

In the meantime there is a counterargument. Anyone who wants to work on a field that is specifically Dutch has to master the Dutch language. If not, all necessary documentary sources - the primary object of research-will not be accessible and stay unknown. Some examples can be found by looking at some of the most excellent American colleagues. Margaret Jacob for instance, a distinguished professor of history at UCLA, learned how to read Dutch, because she is interested in the field of European Enlightenment. She cannot write Dutch nor have scholarly conversations in Dutch, but she knows how to read the sources. Her books and articles are written in English though. And as a consequence, the Dutch influence on what was generally regarded as an Anglo-French movement, could be acknowledged.

Nationalism is a killer in the world of science, also in the humanities. My example is Dutch and therefore humble. But if I were French or German, I would say the same. Again, I am saying this in full awareness of the new nationalism that spreads its bad seeds all over Europe.

7. The final aspect is the level of organization within the humanities or maybe better formulated: the lack of it. If one still thinks of the humanities as a collection of individuals writing individual books, then there is absolutely no need whatsoever to have an internal or external form of organization. But if one agrees that this image of the humanities is no longer true or only partially true, organization becomes a substantial factor. Again the problem is that we are talking about something highly complex. Because there are several fields where scholars could-and to my opinion should - be better organized. Within the discipline or sub-discipline, within the managerial organization (departments, schools, research institutes, fac- 
ulties of humanities), the national endowment organizations of the humanities, the European Science Foundation and/or the European Research Council.

To make a shortcut: we, humanists, are not well organized. Look at the astronomers. The amounts of public money that flows in their direction are not matched with any economic or social outcome at all. Only a few days ago one of the headlines in the Dutch media was the discovery of a new solar system thirteen billion lightyears away from us. The last known solar system is only 12.9 billion lightyears away. Experts said the discovery is of the highest importance. Why? They didn't tell. They almost never do. We speak about 'An Astronomous Amount'. Imagine we would speak of a 'Humanist Amount of Money'. Apart from many other reasons, the astronomers are extremely well organized. That is to say: they fight most of their paradigmatic battles inside their home, with the door shut, the windows closed and the curtains down. When they come outside, they are all astronomers in clean suits. Nature and Science are full of their latest discoveries and they have armies of well-trained scholars who are able and paid to translate the most obscure particles of new knowledge to a broader audience. They have agreed upon an excellent division of labor: doing this in one country, and that in the other. I always wondered why astronomy was such a big thing in The Netherlands: a country that the sun hates profoundly. They work on their research individually and at the same time in small and large groups. Fifteen years ago the Dutch government announced that a limited amount of research proposals could be awarded a large sum of money. The astronomers won by a landslide. Their proposal was written by a journalist and was called Unraveling the Universe. Can you imagine? Newspapers all over the world: 'Dutch unravel Universe!'

With regard to the humanities, there are fields that are highly successfull and well organized at the same time. Like archeology, but even more so linguistics and parts of history, especially social-economic history. If one takes linguistics: the domain is torn apart by fighting paradigms. Syntax, semantics, phonetics, neurocognition, Chomsky or not Chomsky. But they are well organized, share the same publication platforms, have their recognized international conferences, are willing to work on interdisciplinary projects-just think of neurolinguistics and the impact on questions of speech impediment over the last decade. It cannot be a coincidence that this part of the humanities is already working with laboratories and large data collections. Linguistics was recently put on the ESFRI-list, the European Roadmap for large scientific infrastructure.

Should we all copy linguistics? Of course not. But we should look from a more abstract point of view at the process of organization. We should start working at several levels at a time. At the lowest level, begin to look at the field of a discipline or of a group of disciplines. Let's say Literary Studies, to stick to my own academic field. At the same time maybe we should organize the process of research assessment on a national level, like Norway, Denmark and Belgium are doing. Of course benchmarking is one of the necessary factors, but in this way we could avoid sinking to the bottom immediately. I really am convinced that Germany is doing the right thing in selecting a limited number of universities and labeling them as research universities 
and subsequently giving them proportionate more amounts of money. Of course one can criticize the criteria, but still.

I think that we as humanists do not prepare ourselves well enough for the future if we continue to put our research on the website only at the level of individual faculty members. We should have more research projects, more research institutes within the universities and not outside university. We should definitely stop telling the world that we are different. Research assessment is a complicated thing, not in the sense of too difficult or impossible, but in the sense of complex. Let's take all the different parameters into account, let's take time but move on. But the most important thing is: let's take or keep the lead.

Two years ago in The Netherlands a nationwide project started called Sustainable Humanities. It is a plea for more money for the Humanities. But not a traditional plea bargain in the sense of: o, world, look at those poor exotic disciplines, see how they are withering like beautiful flowers blossoming for the last time all alone in the desert with no water. On the contrary. The statement is: look at the enormous quantities of students in media studies, in history, in communication, see how our staff-studentratio does not even come close to that of high schools. Many university professors in the humanities have such a heavy teaching load that it becomes almost impossible to do serious research. Look at our Nachwuchs: the ridiculous small amount of Ph.D. and Postdoc positions.

The project also contains a call to the Humanities itself to start a nationwide process of research assessment. To quote the report:

In addition to peer review, international assessment of research increasingly makes use of bibliometric instruments such as citation indexes and impact factors. These are parameters which can be used in science, technology and medicine. But it is now widely acknowledgedalso internationally - that these instruments are not necessarily suitable for determining the quality of research in the humanities. For example, in 2000 the European Science Foundation (ESF) concluded that the Arts and Humanities Citation Index (AHCI) and the Science Citation Index of the ISI (Institute for Scientific Information, Philadelphia) should not be used by policy makers in Europe. For the humanities these indexes are notoriously unreliable because of the predominance of English-language literature-particularly literature published in the United States - and because of the fact that books are not included in them. The European Reference Index for the Humanities (ERIH) which has since been developed under the auspices of the ESF has certainly not yet been operationalized to the point that it fills this gap. The problem is not so much that proper quality determination is impossible in the humanities. What is missing is an effective instrument that can take the specific character of humanities research into account while measuring quality across an academic field. Because of the special character of these subjects, the benchmarks used to assess them must always be special as well. The fact that relatively few prizes are awarded in this domain aggravates this lack of indicators and makes it even more difficult for outsiders to judge the quality of research (and researchers) in the humanities. Much too often this causes serious problems for top-ranking scholars in the humanities. (Committee on the National Plan for the Future of the Humanities 2009, p. 34)

Therefore the Dutch Royal Academy of Arts and Sciences has taken up the challenge and published a national report on research assessment within the humanities (Royal Netherlands Academy of Arts and Sciences 2011). 
The recognition of the humanities as a distinct member of the body of academic knowledge, leads to the conclusion that humanists should take the steering wheel in developing adequate forms of research assessment themselves. If we leave it to others, the humanities will look like arms attached to the feet.

Open Access This chapter is distributed under the terms of the Creative Commons AttributionNoncommercial 2.5 License (http://creativecommons.org/licenses/by-nc/2.5/) which permits any noncommercial use, distribution, and reproduction in any medium, provided the original author(s) and source are credited.

The images or other third party material in this chapter are included in the work's Creative Commons license, unless indicated otherwise in the credit line; if such material is not included in the work's Creative Commons license and the respective action is not permitted by statutory regulation, users will need to obtain permission from the license holder to duplicate, adapt or reproduce the material.

\section{References}

Committee on the National Plan for the Future of the Humanities. (2009). Sustainable humanities: Report from the committee on the national plan for the future of the humanities. Amsterdam: Amsterdam University Press. http://www.oapen.org/search?identifier=339995.

Royal Netherlands Academy of Arts and Sciences. (2011). Quality indicators for research in the humanities. Amsterdam: Royal Netherlands Academy of Arts and Sciences. https://www.knaw. $\mathrm{nl} /$ shared/resources/actueel/publicaties/pdf/quality-indicators-for-research-in-the-humanities. 